\title{
Impact of Chronic Kidney Disease on the Presence and Severity of Aortic Stenosis in Patients at High Risk for Coronary Artery Disease
}

\author{
Chiaki Masuda', Kaoru Dohi ${ }^{2}$, Yuko Sakurai ${ }^{1}$, Yuri Bessho ${ }^{1}$, Harumi Fukuda', Shinobu Fujii ${ }^{1}$, Tadafumi Sugimoto ${ }^{3}$, \\ Masaki Tanabe ${ }^{3}$, Katsuya Onishi ${ }^{3}$, Katsuya Shiraki ${ }^{4}$, Masaaki Ito $^{3}$ and Tsutomu Nobori $^{2}$
}

\begin{abstract}
Objective: We evaluated the impact of chronic kidney disease (CKD) on the presence and severity of aortic stenosis (AS) in patients at high risk for coronary artery disease (CAD).

Methods: One hundred and twenty consecutive patients who underwent invasive coronary angiography were enrolled. Aortic valve area (AVA) was calculated by the continuity equation using transthoracic echocardiography, and was normalized by body surface area (AVA index).

Results: Among all 120 patients, 78\% had CAD, 55\% had CKD (stage 3: 81\%; stage 4: 19\%), and 34\% had AS (AVA < $2.0 \mathrm{~cm}^{2}$ ). Patients with AS were older, more often female, and had a higher frequency of CKD than those without AS, but the prevalence of CAD and most other coexisting conventional risk factors was similar between patients with and without AS. Multivariate linear regression analysis indicated that only CKD and CAD were independent determinants of AVA index with standardized coefficients of -0.37 and -0.28 , respectively. When patients were divided into 3 groups (group 1: absence of CKD and CAD, $n=16$; group 2: presence of either CKD or CAD, $n=51$; and group 3: presence of both CKD and CAD, $n=53)$, group 3 had the smallest AVA index $\left(1.19 \pm 0.30^{*} \# \mathrm{~cm}^{2} / \mathrm{m}^{2},{ }^{*} p<0.05\right.$ vs. group 1: $1.65 \pm$ $0.32 \mathrm{~cm}^{2} / \mathrm{m}^{2}$, and $\# p<0.05$ vs. group $2: 1.43 \pm 0.29^{*} \mathrm{~cm}^{2} / \mathrm{m}^{2}$ ) and the highest peak velocity across the aortic valve (1.53 $\pm 0.41^{*} \# \mathrm{~m} / \mathrm{sec}^{*}{ }^{*} \mathrm{p}<0.05$ vs. group 1: $1.28 \pm 0.29 \mathrm{~m} / \mathrm{sec}$, and \#p $<0.05$ vs. group 2: $\left.1.35 \pm 0.27 \mathrm{~m} / \mathrm{sec}\right)$.
\end{abstract}

Conclusion: CKD, even pre-stage 5 CKD, has a more powerful impact on the presence and severity of AS than other conventional risk factors for atherosclerosis in patients at high risk for CAD.

Keywords: Echocardiography, Aortic valve area, Coronary artery disease, Chronic kidney disease

\section{Introduction}

Calcific aortic valve disease is associated with increased cardiovascular risk [1,2]. There are significant similarities in clinical risk factors and histopathological alterations between calcific aortic valve disease and coronary atherosclerosis [3]. It is also widely recognized that both cardiac and renal diseases are commonly present in the same patient, and the presence of chronic kidney disease (CKD) further accelerates and amplifies the process of aortic valve calcification via multiple pathways, such as altered mineral metabolism, inflammation, oxidative

\footnotetext{
* Correspondence: dohik@clin.medic.mie-u.ac.jp

${ }^{2}$ Department of Molecular and Laboratory Medicine, Mie University Graduate School of Medicine

Full list of author information is available at the end of the article
}

stress, and pressure and volume overload $[4,5]$. Previous studies have demonstrated an association between endstage renal disease and calcific cardiovascular disease, especially in patients on dialysis [6-9]; however, less is known about the impact of early stage CKD on the prevalence and severity of calcific aortic valve disease. Accordingly, we tested the hypothesis that patients with early stage CKD not yet on dialysis who are at high risk for coronary atherosclerosis have an increased risk for developing calcific aortic valve disease.

\section{Patients and Methods \\ Study Population}

We prospectively evaluated the presence and severity of calcific aortic valve disease in a consecutive series of 146

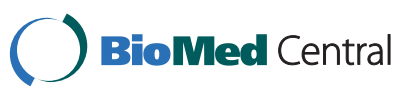


patients who underwent coronary angiography between September 2009 and March 2010 because of suspected coronary artery disease or for follow up angiography after coronary angioplasty or coronary artery bypass graft surgery. We excluded 1 patient with rheumatic heart disease, 1 patient with severe aortic regurgitation due to infective endocarditis, 1 patient with a bicuspid aortic valve, and 8 patients with prosthetic valves due to specific pathophysiologic conditions that affect the aortic valve area other than "calcific" aortic stenosis. One patient with known severe aortic stenosis who was referred to our hospital for preoperative evaluation, not for the suspicion of coronary artery disease, was also excluded. Nine patients with end-stage renal disease treated with hemodialysis were not included in the present study to exclude the confounding effect of hemodialysis on the progression of aortic valve sclerosis. Five patients with severe mitral regurgitation caused by valve disease were excluded because the aortic valve area in these patients can be underestimated due to their low-flow state, even if the aortic valve is normal. Accordingly, the patient study group consisted of 120 patients (mean age $67 \pm 13$ years, 33-91 years, 97 males). CKD was defined as kidney damage or the presence of an estimated glomerular filtration rate $(\mathrm{eGFR})<60 \mathrm{ml} / \mathrm{min} / 1.73 \mathrm{~m}^{2}$ for 3 months or more, irrespective of cause $[10,11]$. The eGFR of each patient was calculated from their serum creatinine (SCr) value and their age using the following equation [12]: $\operatorname{eGFR}\left(\mathrm{ml} / \mathrm{min} / 1.73 \mathrm{~m}^{2}\right)=194 \times \mathrm{Age}^{-0.287} \times \mathrm{SCr}^{-1.094}$ (if female $\times 0.739$ ). Kidney damage was ascertained by the presence of albuminuria, defined as albumin-to-creatinine ratio $>30 \mathrm{mg} / \mathrm{g}$ in two of three spot urine specimens $[10,11]$. CKD was staged according to accepted NIH/ NIDDK Kidney Disease Outcomes Quality Initiative standards [11]. The protocol was approved for use by the Human Studies Subcommittee of Mie University Graduate School of Medicine.

\section{Echocardiography}

All patients underwent complete transthoracic echocardiography using a Vivid 7 system (GE-Vingmed, Horten, Norway) and an Aplio Artida ultrasound system (Toshiba Medical Systems Corp., Tokyo, Japan) within 2 months before or after coronary angiography. Arm-cuff blood pressure measurements were performed at the beginning of each echocardiographic study for all patients. The size of the aorta and left atrium, interventricular and left ventricular (LV) posterior wall thicknesses, LV end-diastolic and end-systolic dimensions, and fractional shortening were assessed from the parasternal long axis view [13]. The LV outflow tract (LVOT) diameter was measured in the parasternal long-axis view in mid-systole, and then converted to LVOT area (LVOT area $=\pi \times(0.5 \times$ LVOT \left.${\left.\text { diameter })^{2}\right)}^{2} 14,15\right]$. Doppler-derived stroke volume was calculated as the product of the LVOT area and the LVOT velocity time integral (VTI) obtained by pulsed Doppler [15]. The ratio of peak early diastolic transmitral flow velocity to peak early diastole mitral annular velocity $\left(E^{\prime}\right)$ at the lateral site in the mitral annulus (E/E') was calculated as a Doppler parameter reflecting LV filling pressure $[16,17]$. Aortic valve area (AVA) was calculated by the continuity equation; $\mathrm{AVA}=(\mathrm{LVOT}$ are $\times$ LVOT VTI)/trans-aortic VTI $[18,19]$. Severity of aortic stenosis (AS) was defined as follows: severe stenosis, AVA $<1.0$ $\mathrm{cm}^{2}$; moderate stenosis, AVA 1.0 to $1.5 \mathrm{~cm}^{2}$; and mild stenosis, AVA 1.5 to $2.0 \mathrm{~cm}^{2}$ [20]. AVA index, normalized by body surface area, was also calculated [20]. Peak velocity and mean pressure gradient across the aortic valve were also measured [20]. Aortic calcification was defined upon increased thickness and bright echoes of the valve leaflets. All Doppler values represent an average of 3 beats in the case of sinus rhythm and an average of 5 beats in the case of atrial fibrillation.

\section{Coronary Angiography}

Coronary artery disease (CAD) was defined as a history of myocardial infarction, coronaryangioplasty, coronary artery bypass graft surgery, and $a \geq 50 \%$ luminal diameter stenosis in $\geq 1$ epicardial coronary artery by quantitative coronary angiography. Selective catheter coronary angiography was performed via the transradial or transbrachial Judkins approach using standard techniques after nitroglycerin administration. Quantitative coronary angiography was performed using an automated edge-detection system (QAngioXA, MEDIS medical imaging systems, Leiden, the Netherlands) by a single observer unaware of the echocardiographic results. At least 2 orthogonal projections were evaluated, and measurement of percent diameter stenosis was performed in the projection showing the highest degree of narrowing.

\section{Statistical Analysis}

Continuous variables were presented by mean and standard deviation and compared using a Student's t test or the Mann-Whitney's U test. Bonferroni correction was applied for multiple comparisons. Categorical variables were presented as percent frequencies and differences between proportions were compared using $\chi^{2}$ test. Pvalues of less than 0.05 were considered to be statistically significant.

\section{Results}

\section{Clinical characteristics}

All patients underwent successful coronary angiography and transthoracic echocardiography. Of 120 patients, 2 patients $(2 \%)$ had severe AS, 9 patients (8\%) had moderate AS, and 30 patients (25\%) had mild AS. Table 1 shows the clinical characteristics of the study subjects. 
Table 1 Clinical Characteristics of Study Subjects

\begin{tabular}{|c|c|c|}
\hline & Non-AS $(n=79)$ & AS $(n=41)$ \\
\hline \multicolumn{3}{|l|}{ Demographics } \\
\hline Mean age, years & $65 \pm 12$ & $72 \pm 12^{*}$ \\
\hline Female gender, \% & 11 & $34^{*}$ \\
\hline Height, $\mathrm{cm}$ & $165 \pm 8$ & $157 \pm 9^{*}$ \\
\hline Body weight, kg & $65 \pm 12$ & $58 \pm 10^{*}$ \\
\hline Systolic blood pressure, $\mathrm{mmHg}$ & $129 \pm 21$ & $137 \pm 28$ \\
\hline Heart rate, beats/min & $67 \pm 12$ & $69 \pm 14$ \\
\hline \multicolumn{3}{|l|}{ Medical history } \\
\hline Hypertension, \% & 70 & 78 \\
\hline Diabetes mellitus, $\%$ & 34 & 39 \\
\hline Dyslipidemia, \% & 67 & 71 \\
\hline Current smoking, \% & 46 & $20^{*}$ \\
\hline Coronary artery disease, $\%$ & 73 & 85 \\
\hline Chronic kidney disease, \% & 41 & $76^{*}$ \\
\hline \multicolumn{3}{|l|}{ Medication use } \\
\hline Beta blocker, \% & 27 & 29 \\
\hline Calcium channel blocker, \% & 39 & 44 \\
\hline ACEI/ARB, \% & 56 & 66 \\
\hline Diuretics, \% & 20 & 20 \\
\hline Statin, \% & 46 & 46 \\
\hline \multicolumn{3}{|l|}{ Measurements } \\
\hline eGFR, $\mathrm{ml} / \mathrm{min} / 1.73 \mathrm{~m}^{2}$ & $64 \pm 23$ & $53 \pm 18^{*}$ \\
\hline Hemoglobin, g/dl & $13.2 \pm 2.0$ & $12.8 \pm 1.9$ \\
\hline Calcium, mg/dl & $9.4 \pm 0.6$ & $9.5 \pm 0.6$ \\
\hline Phosphate, mg/dl & $3.4 \pm 0.6$ & $3.4 \pm 0.6$ \\
\hline Total cholesterol, mg/dl & $185 \pm 44$ & $182 \pm 30$ \\
\hline HDL-cholesterol, mg/dl & $50 \pm 18$ & $50 \pm 14$ \\
\hline LDL-cholesterol, mg/dl & $108 \pm 36$ & $105 \pm 24$ \\
\hline Triglyceride, mg/dl & $135 \pm 64$ & $131 \pm 55$ \\
\hline Hemoglobin A1C, \% & $6.0 \pm 1.0$ & $6.1 \pm 0.8$ \\
\hline C-reactive protein, mg/dl & $0.20 \pm 0.28$ & $0.32 \pm 0.79$ \\
\hline
\end{tabular}

AS: aortic stenosis; ACEl: angiotensin converting enzyme inhibitor; ARB: angiotensin receptor blocker; eGFR: estimated glomerular filtration rate; HDL: high density lipoprotein; LDL: low density lipoprotein. ${ }^{*} \mathrm{P}<0.05$ versus non-AS.

Patients with AS were older, more often female, and had smaller body sizes than those without AS. The prevalence of coexisting hypertension, diabetes mellitus, and dyslipidemia was similar between the two patient groups, but patients with AS were less often categorized as current smokers than those without AS. Ninety-three of all 120 patients (78\%) had CAD, and $56 \%$ of CAD patients had multi-vessel disease. The prevalence of CAD was similar between patients with and without AS. Of all 120 patients, $53 \%$ had CKD; $81 \%$ of these had stage 3 CKD (eGFR 59 to $30 \mathrm{ml} / \mathrm{min} / 1.73 \mathrm{~m}^{2}$ ) and $19 \%$ had stage 4 CKD (eGFR 29 to $15 \mathrm{ml} / \mathrm{min} / 1.73 \mathrm{~m}^{2}$ ). Patients with AS had a greater occurrence of CKD than those without AS. Patients with and without AS received similar medications. Although patients with AS had lower eGFR than those without AS, serum hemoglobin, calcium, and phosphate levels were similar between the two patients groups. Plasma lipid profile levels, hemoglobin A1C, and c-reactive protein were not significantly different between the two patient groups.

\section{Echocardiographic Data}

Table 2 shows the echcardiographic data from the study subjects. LV geometry and fractional shortening were similar between patients with and without AS. LVOT diameter and stroke volume were lower in patients with AS; however, stroke volume index was similar between patients with and without AS $\left(33 \pm 9\right.$ and $36 \pm 8 \mathrm{ml} / \mathrm{m}^{2}$, $\mathrm{p}=\mathrm{ns})$. E/E' was similar between patients with and without AS. Aortic valve calcification was more frequent in patients with AS compared to those without AS. Peak velocity and the mean pressure gradient across the aortic valve during ejection were higher and AVA was smaller in patients with AS compared to those without AS.

\section{Determinants of AVA Index}

Multivariate linear regression analysis was used to identify clinical (age, gender, blood pressures, presences of hypertension, diabetes mellitus, dyslipidemia, current smoking, CAD, CKD, medication uses, and laboratory measurements) and echocardiographic variables that might predict AVA index with a stepwise method. The results indicated that only the presence of CKD and CAD were independent determinants of AVA index with standardized coefficients of -0.37 and -0.28 , respectively. Figures 1 and 2 show typical examples of 2-dimentioal and Doppler echocardiographic appearances of the aortic valve in a patient without CKD or CAD, and a patient with both CKD and CAD, respectively. The patient without CKD or CAD (62 year-old male, eGFR: $78 \mathrm{ml} / \mathrm{min} /$ $1.73 \mathrm{~m}^{2}$ ) had non-calcified aortic valve with calculated AVA of $3.2 \mathrm{~cm}^{2}$ (Figure 1). In contrast, the patient with both CKD and CAD (77 year-old male, eGFR: $48 \mathrm{ml}$ / $\min / 1.73 \mathrm{~m}^{2}$, 1 vessel disease) had a restricted aortic valve with calculated AVA of $1.7 \mathrm{~cm}^{2}$ and a turbulent flow across the valve with peak velocity of $2.2 \mathrm{~m} / \mathrm{sec}$ (Figure 2). When dividing patients into 3 groups according to the presence or absence of CKD and CAD (group 1: absence of CKD and CAD; group 2: presence of either CKD or CAD; group 3: presence of both CKD and CAD), group 2 had significantly lower AVA index than group 1, and group 3 had significantly lower AVA index than both groups 1 and 2 (group 1: $1.65 \pm 0.32 \mathrm{~cm}^{2} / \mathrm{m}^{2}$; group 2: $1.43 \pm 0.29 * \mathrm{~cm}^{2} / \mathrm{m}^{2}$; and group 3: $1.19 \pm 0.30 * \#$ $\mathrm{cm}^{2} / \mathrm{m}^{2}$; * $\mathrm{p}<0.05$ vs. group 1 , and \# $<0.05$ vs. group 2 , respectively; Figure 3 ). Peak velocity across the aortic valve was significantly higher in the group 3 than both groups 1 and 2 (group 1: $1.28 \pm 0.29 \mathrm{~m} / \mathrm{sec}$; group 2: $1.35 \pm 0.27 \mathrm{~m} / \mathrm{sec}$; and group 3: $1.53 \pm 0.41 * \mathrm{~m} / \mathrm{sec}$; ${ }^{*} \mathrm{p}<$ 0.05 vs. group 1 , and \#p $<0.05$ vs. group 2 , respectively; Figure 4). 


\section{Table 2 Echocardiographic Data of Study Subjects}

\begin{tabular}{|c|c|c|}
\hline & Non-AS $(n=79)$ & AS $(n=41)$ \\
\hline Aortic diameter, $\mathrm{mm}$ & $30 \pm 3$ & $29 \pm 2$ \\
\hline Left atrial diameter, $\mathrm{mm}$ & $38 \pm 6$ & $39 \pm 8$ \\
\hline Interventricular septal thickness, mm & $10 \pm 2$ & $10 \pm 2$ \\
\hline Posterior wall thickness, $\mathrm{mm}$ & $10 \pm 2$ & $10 \pm 2$ \\
\hline LV end-diastolic diameter, mm & $50 \pm 8$ & $48 \pm 7$ \\
\hline LV end-systolic diameter, mm & $36 \pm 10$ & $34 \pm 9$ \\
\hline Fractional shortening, $\%$ & $30 \pm 10$ & $30 \pm 9$ \\
\hline LV outflow diameter, mm & $21 \pm 1$ & $20 \pm 2^{*}$ \\
\hline Stroke volume, $\mathrm{ml}$ & $60 \pm 12$ & $52 \pm 15^{*}$ \\
\hline$E / E^{\prime}$ & $9 \pm 4$ & $11 \pm 6$ \\
\hline Aortic valve calcification, $\%$ & 30 & $68^{*}$ \\
\hline Peak velocity across the aortic valve, $\mathrm{m} / \mathrm{s}$ & $1.27 \pm 0.21$ & $1.70 \pm 0.41^{*}$ \\
\hline Mean pressure gradient across the aortic valve, $\mathrm{mmHg}$ & $3.53 \pm 1.17$ & $6.20 \pm 3.28^{*}$ \\
\hline Aortic valve area, $\mathrm{cm}^{2}$ & $2.58 \pm 0.39$ & $1.62 \pm 0.33^{*}$ \\
\hline
\end{tabular}

AS: aortic stenosis; LV: left ventricular; E/E': ratio of peak early diastolic transmitral flow velocity to peak early diastole mitral annular velocity. ${ }^{*} \mathrm{P}<0.05$ versus non-AS.

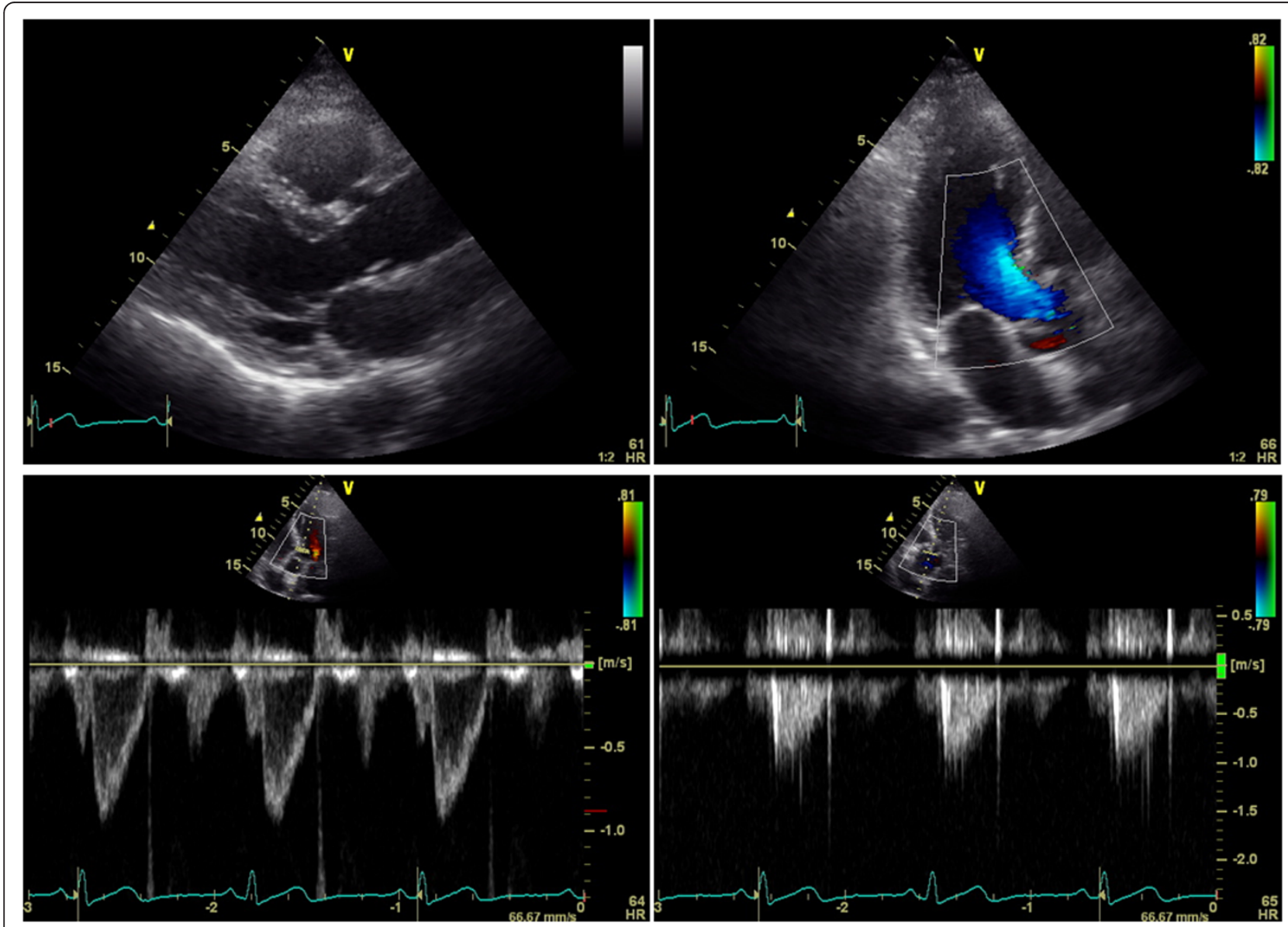

Figure 1 Two-dimentioal and Doppler echocardiographic images from a patient without CKD or CAD. CKD: chronic kidney disease; CAD: coronary artery disease. 

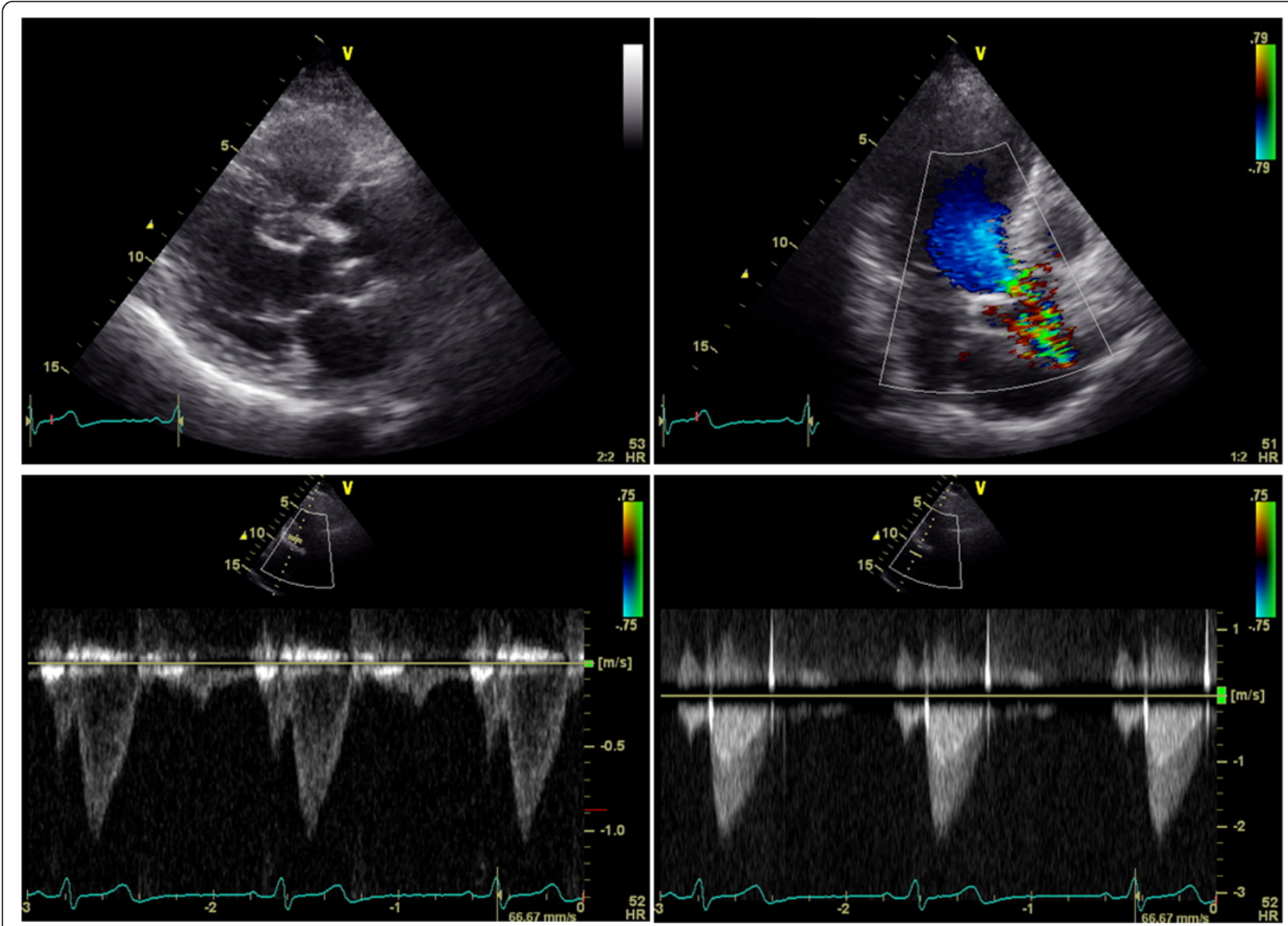

Figure 2 Two-dimentioal and Doppler echocardiographic images from a patient with both CKD and CAD. CKD: chronic kidney disease; CAD: coronary artery disease.

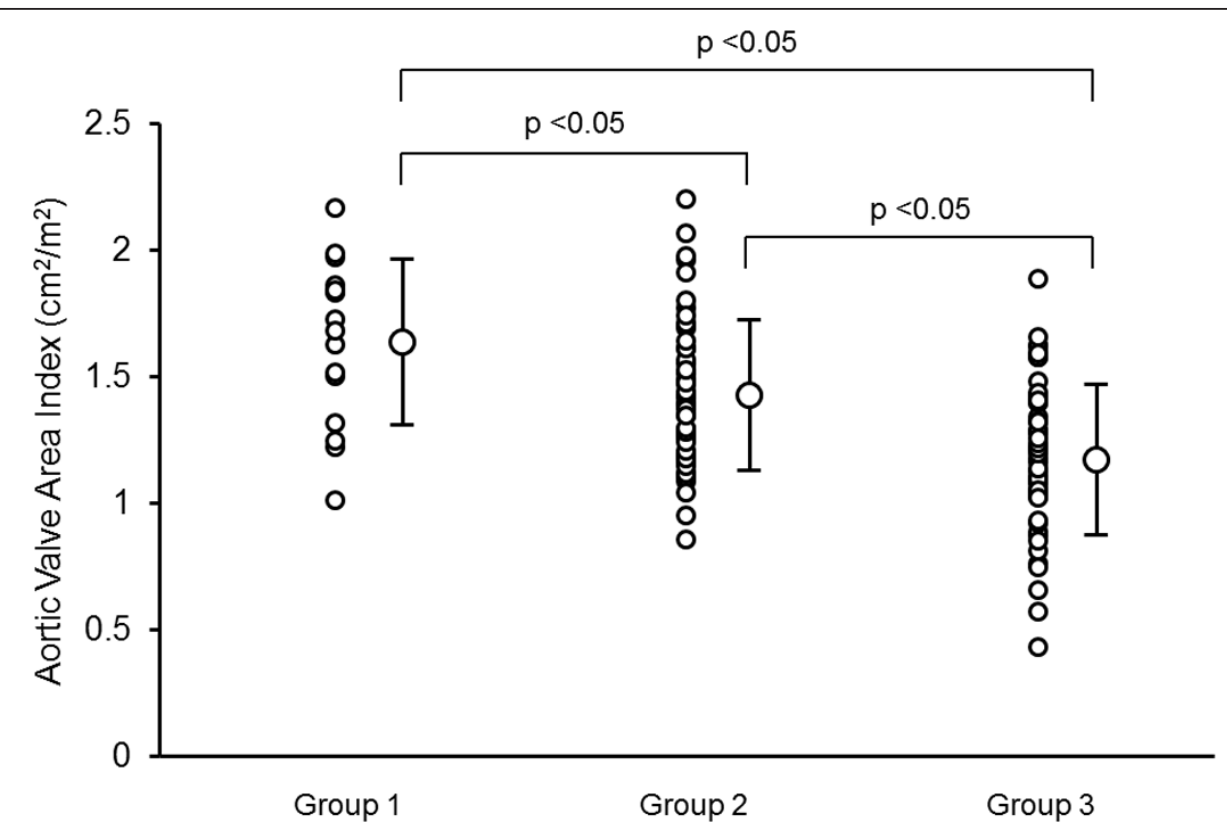

Figure 3 Plots showing aortic valve area index in group 1 (absence of CKD and CAD, $n=16$ ), group 2 (presence of either CKD or CAD, $n=51$ ), and group 3 (presence of both CKD and CAD, $n=53$ ). CKD: chronic kidney disease; CAD: coronary artery disease. 


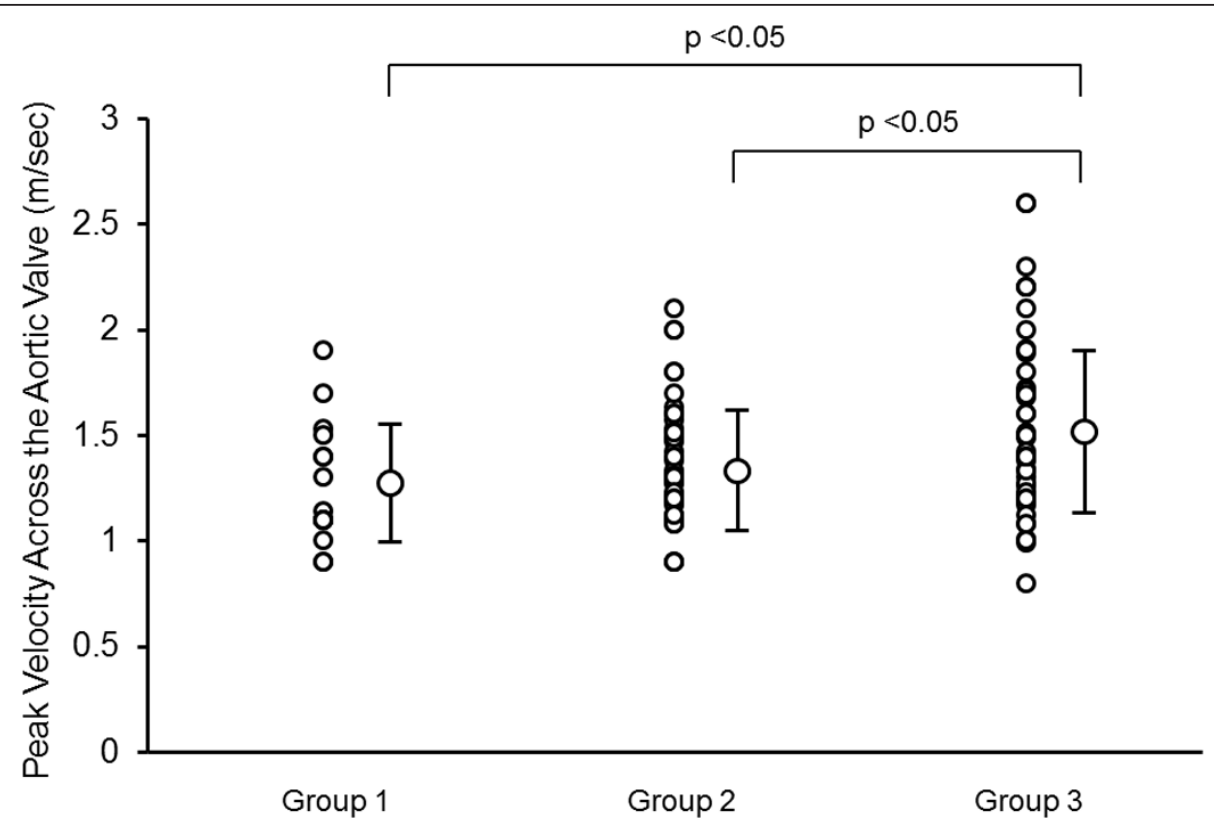

Figure 4 Plots showing peak velocity across the aortic valve in group 1 (absence of CKD and CAD, $n=16$ ), group 2 (presence of either CKD or CAD, $n=51$ ), and group 3 (presence of both CKD and CAD, $n=53$ ). CKD: chronic kidney disease; CAD: coronary artery disease.

\section{Discussion}

We quantified the AVA index by transthoracic echocardiography in consecutive patients receiving coronary angiography and clarified that CKD, even pre-stage 5 CKD, was the most powerful determinant of AVA index among a high risk population for coronary atherosclerosis.

Calcific aortic valve disease is frequent in the general population and is associated with high cardiovascular risk $[1,2]$. This valvular disease is a slowly progressive disorder with a disease continuum that ranges from mild valve thickening without obstruction of blood flow, termed aortic sclerosis, to severe calcification with impaired leaflet motion, or AS [21]. The pathologic mechanisms involved in the disease include active processes that are similar to those occurring in coronary atherosclerosis, such as the impairment of endothelium, inflammation, and lipid infiltration [21-23]. Thus, calcific aortic valve disease has been widely shown to correlate with the presence and severity of CAD $[3,24,25]$.

Despite the similarities in the histopathologic features and clinical factors associated with calcific aortic valve disease and coronary atherosclerosis, however, discrepancies also exist. For example, although calcific changes can be seen in the atherosclerotic plaques of coronary arteries, calcification occurs earlier and is a more prominent feature of calcific aortic valve disease, particularly in the end stages of the disease process, and a large contributor of disease progression is prominent calcification with a gradual increase in leaflet thickness and outflow obstruction [26]. The importance of tissue calcification in the disease process is highlighted by the observation that subsets of patients with altered mineral metabolism such as CKD have a higher prevalence of calcific aortic valve disease and more rapid disease progression [6-9]. However, most previous studies have demonstrated an association between end-stage renal disease and calcific cardiovascular disease, especially in patients on dialysis [6-9], and therefore, less is known about the impact of early stage CKD on the prevalence and severity of calcific aortic valve disease. The present study indicates that patients with early stage CKD have an increased prevalence of AS in the populations at high risk for coronary atherosclerosis. Notably, most of patients with CKD in the present study were in stage 3 , and mean eGFR in patients with and without AS was $64 \pm 23$ and $53 \pm 18$ $\mathrm{ml} / \mathrm{min} / 1.73 \mathrm{~m}^{2}$, respectively, suggesting that small differences in renal function in early stages CKD can contribute to the progression of calcific aortic valve disease in patients at high risk for coronary atherosclerosis. Although it would be difficult to address the underlying mechanisms that are responsible for the progression of calcific aortic valve disease in these earlier stages of CKD, the present study suggests that latent alterations in multiple factors such as inflammation, anemia, oxidative stress, abnormal calcium/phosphate metabolism, and hemodynamic overload may interdependently contribute to the disease process, even when serum calcium/phosphate levels are within normal ranges, and c-reactive protein 
levels, hemoglobin levels, and echocardiographic parameters of LV filling pressure are statistically similar between patients with and without AS. Although the present study did not focus on activation of proinflammatory mechanisms as a causal mechanism for the progression of calcific aortic valve disease, Aikawa et al demonstrated that proinflammatory cathepsin S, a highly potent elastase, contributes to arterial and valvular calcification in mice with atherosclerosis and CKD assessed by in vivo and ex vivo optical molecular imaging [27]. They used molecular imaging of early calcification and elastolytic activity to address new mechanisms underlying accelerated calcification in patients with CKD and suggested that calcification is a multifactorial process induced by proinflammatory stimuli that promote accumulation of elastolytic macrophages. Although the present study did not focus on abnormalities in mineral metabolism as a causal mechanism for the progression of calcific aortic valve disease, previous clinical studies have demonstrated that a decrease in 1,25-dihydroxyvitamin $\mathrm{D}$ and an increase in parathyroid hormone (PTH) are the earliest mineral metabolic events that take place in CKD, while serum calcium and phosphate levels are altered later in the course of CKD [28]. Adeney et al. demonstrated that higher serum phosphate concentrations within the normal laboratory range were associated with a statistically greater prevalence of coronary artery, descending thoracic aorta, and mitral valve calcification in a communitybased cohort of individuals with moderate CKD and no clinically apparent cardiovascular disease [29]. A decline in renal function leads to phosphate retention, elevated PTH levels, and low 1,25-dihydroxy vitamin D levels; however, serum phosphate levels are often maintained within the normal laboratory range until relatively late in the course of CKD [30-32]. Therefore, evaluation of the levels of serum PTH and 1,25-dihydroxy vitamin D, early markers for impaired mineral metabolism, is important to clarify the underlying mechanisms that are responsible for the progression of calcific aortic valve disease in early stage CKD.

Several studies have documented an overlap in the clinical factors traditionally associated with calcific valve disease and coronary atherosclerosis [33-38]. In the prospective population-based Cardiovascular Health Study, which included 5621 adults over the age of 65 years, clinical factors associated with calcific aortic valve disease included age, gender, smoking, hypertension, and hyperlipidemia [33]. However, CKD was not included as a potential contributor to aortic valve calcification and stenosis in these studies. In contrast, our study demonstrated that conventional risk factors for cardiovascular atherosclerosis were not independently related to the progression of aortic valve disease, possibly because they were well-controlled. Despite receiving adequate risk factor management, more than half of the patients developed CKD in the present study, and CKD, even pre-stage $5 \mathrm{CKD}$, has a more powerful impact on the presence and severity of AS than other conventional risk factors for atherosclerosis in patients at high risk for CAD. These results indicate that patients with CKD should be included as part of the highest risk group for the progression of calcific aortic valve disease. Aortic valve calcification impairs the movement of aortic valve leaflets, which affects cardiac function, and can only be alleviated through costly and invasive procedures. Therefore, early diagnosis of and interference with aortic valve calcification could provide enormous clinical benefits.

Although 34\% of patients were diagnosed with AS based on AVA, the average value of their peak velocities and mean pressure gradients across the aortic valve were only $1.70 \pm 0.41 \mathrm{~m} / \mathrm{sec}$ and $6.20 \pm 3.28 \mathrm{mmHg}$, respectively. Patients with AS in our study population were older, had smaller body size, were more often women, and had smaller LVOT diameter compared with those without AS, which may partially be associated with low-flow and lowgradient AS [39]. Nevertheless, the present study demonstrated that presence of both with CKD and CAD had a great impact on reduced AVA index and elevated peak velocity across the aortic valve.

A potential limitation of the present study was the small sample population, although we succeeded in testing our primary hypothesis, which showed the impact of CKD on the presence and the severity of AS in patients at high risk for CAD. Three dimensional measurements of LVOT and aortic valve area were not involved in this study. However, Doppler-derived estimation of AVA using two-dimensional transthoracic echocardiography is considered to correlate well with simultaneous catheter-derived measurements, and is widely used clinically [14-16]. Invasive pressure measurements were not involved in the present study; therefore, evaluation of AVA using Gorlin's formula was not possible. Also, direct measures of LV end-diastolic pressure or pulmonary wedge pressure were not possible. Accordingly, E/E' was recruited as a marker of LV filling pressure in the present study $[17,18]$. Finally, evaluation of the rate of progression of aortic stenosis or the clinical outcome was not included in our study. The long-term effect of CKD on the progression of calcific aortic valve disease warrants further investigation.

\section{List of abbreviations}

CKD: chronic kidney disease; AS: aortic stenosis; CAD: coronary artery disease; AVA: aortic valve area; eGFR: estimated glomerular filtration rate; SCr: serum creatinine; LV: left ventricular; LVOT: outflow tract; VTI: velocity time integral; $E^{\prime}$ : peak early diastole mitral annular velocity; $E / E^{\prime}$ : The ratio of peak early diastolic transmitral flow velocity to peak early diastole mitral annular velocity; PTH: parathyroid hormone. 


\section{Acknowledgements}

The authors are grateful to GE Healthcare and Toshiba Medical Systems Corp. for technical support.

\section{Author details}

${ }^{1}$ Central Laboratory, Mie University Graduate School of Medicine. ${ }^{2}$ Department of Molecular and Laboratory Medicine, Mie University Graduate School of Medicine. ${ }^{3}$ Department of Cardiology and Nephrology, Mie University Graduate School of Medicine. ${ }^{4}$ Department of Gastroenterology, Mie University Graduate School of Medicine.

\section{Authors' contributions}

$C M, Y S, Y B, H F$, and SF acquired the ultrasound images and performed the analysis. CM and KD contributed substantially to data interpretation and wrote the manuscript. KD contributed substantially to the conception and design of the study, and critical revision of the manuscript for important intellectual content. TS and MS assisted in data interpretation. KO and KS contributed to critical revision of the manuscript for important intellectual content and study supervision. MI and TN reviewed the manuscript. Finally, all authors read and approved the manuscript.

\section{Competing interests}

The authors declare that they have no competing interests.

Received: 2 August 2011 Accepted: 16 November 2011 Published: 16 November 2011

\section{References}

1. Otto CM, Lind BK, Kitzman DW, Gersh BJ, Siscovick DS: Association of aortic-valve sclerosis with cardiovascular mortality and morbidity in the elderly. N Engl J Med 1999, 341:142-147.

2. Rosenhek R, Klaar U, Schemper M, Scholten C, Heger M, Gabriel H, Binder T, Maurer G, Baumgartner H: Mild and moderate aortic stenosis: natural history and risk stratification by echocardiography. Eur Heart J 2004, 25:199-205.

3. Sui SJ, Ren MY, Xu FY, Zhang Y: A high association of aortic valve sclerosis detected by transthoracic echocardiography with coronary arteriosclerosis. Cardiology 2007, 108:322-330.

4. Braun J, Oldendorf M, Moshage W, Heidler R, Zeitler E, Luft FC: Electron beam computed tomography in the evaluation of cardiac calcification in chronic dialysis patients. Am J Kidney Dis 1996, 27:394-401.

5. Perkovic V, Hunt D, Griffin SV, du Plessis M, Becker GJ: Accelerated progression of calcific aortic stenosis in dialysis patients. Nephron Clin Pract 2003, 94:c40-c45.

6. Floege J, Ketteler M: Vascular calcification in patients with end-stage renal disease. Nephrol Dial Transplant 2004, 19(suppl 5):V59-V66.

7. Sarnak MJ, Levey AS, Schoolwerth AC, Coresh J, Culleton B, Hamm LL, McCullough PA, Kasiske BL, Kelepouris E, Klag MJ, Parfrey P, Pfeffer M, Raii L, Spinosa DJ, Wilson PW: Kidney disease as a risk factor for development of cardiovascular disease: a statement from the American Heart Association Councils on Kidney in Cardiovascular Disease, High Blood Pressure Research, Clinical Cardiology, and Epidemiology and Prevention. Circulation 2003, 108:2154-2169.

8. Ureña P, Malergue MC, Goldfarb B, Prieur P, Guédon-Rapoud C, Pétrover M: Evolutive aortic stenosis in hemodialysis patients: analysis of risk factors. Nephrologie 1999, 20:217-225.

9. Raggi P, Boulay A, Chasan-Taber S, Amin N, Dillon M, Burke SK, Chertow GM: Cardiac calcification in adult hemodialysis patients. A link between end-stage renal disease and cardiovascular disease? J Am Coll Cardiol 2002, 39:695-701.

10. Stevens LA, Coresh J, Greene T, Levey AS: Assessing kidney functionmeasured and estimated glomerular filtration rate. N Engl J Med 2006, 354:2473-2483.

11. National Kidney Foundation: K/DOQI clinical practice guidelines for chronic kidney disease: evaluation, classification, and stratification. Part 4. Definition and classification of stages of chronic kidney disease. Am J Kidney Dis 2002, 39(Suppl 1):S46-S75.

12. Matsuo S, Imai E, Horio M, Yasuda Y, Tomita K, Nitta K, Yamagata $K$, Tomino $Y$, Yokoyama $H$, Hishida $A$, on behalf of the collaborators developing the Japanese equation for estimated GFR: Revised equations for estimated GFR from serum creatinine in Japan. Am J Kidney Dis 2009, 53:982-992.

13. Members of the Chamber Quantification Group: Recommendations for chamber quantification: A report from the American Society of Echocardiography's Guidelines and Standards Committee and the Chamber Quantification Writing Group, developed in conjunction with the European Association of Echocardiography, a branch of the European Society of Cardiology. J Am Soc Echocardiogr 2005, 18:1440-1463.

14. Singh B, Mohan JC: Doppler echocardiographic determination of aortic and pulmonary valve orifice areas in normal adult subjects. Int I Cardiol 1992, 37:73-78.

15. Quinones MA, Otto CM, Stoddard M, Waggoner A, Zoghbi WA: Recommendations for quantification of Doppler echocardiography: a report from the Doppler Quantification Task Force of the Nomenclature and Standards Committee of the American Society of Echocardiography. J Am Soc Echocardiogr 2002, 15:167-184.

16. Garcia MJ, Rodriguez L, Ares M, Griffin BP, Thomas JD, Klein AL: Differentiation of constrictive pericarditis from restrictive cardiomyopathy: assessment of left ventricular diastolic velocities in longitudinal axis by Doppler tissue imaging. J Am Coll Cardiol 1996, 27:108-114.

17. Nagueh SF, Middleton KJ, Kopelen HA, Zoghbi WA, Quinones MA: Doppler tissue imaging: a noninvasive technique for evaluation of left ventricular relaxation and estimation of filling pressures. J Am Coll Cardiol 1997, 30:1527-1533.

18. Zoghbi WA, Farmer KL, Soto JG, Nelson JG, Quinones MA: Accurate noninvasive quantification of stenotic aortic valve area by Doppler echocardiography. Circulation 1986, 73:452-459.

19. Oh JK, Taliercio CP, Holmes DR Jr, Reeder GS, Bailey KR, Seward JB, Tajik AJ: Prediction of the severity of aortic stenosis by Doppler aortic valve area determination: prospective Doppler-catheterization correlation in 100 patients. J Am Coll Cardiol 1988, 11:1227-1234.

20. Bonow RO, Carabello BA, Kanu C, de LA Jr, Faxon DP, Freed MD, Gaasch WH, Lytle BW, Nishimura RA, O'Gara PT, O'Rourke RA, Otto CM, Shah PM, Shanewise JS: ACC/AHA 2006 guidelines for the management of patients with valvular heart disease: a report of the American College of Cardiology/American Heart Association Task Force on Practice Guidelines (writing committee to revise the 1998 Guidelines for the Management of Patients With Valvular Heart Disease): developed in collaboration with the Society of Cardiovascular Anesthesiologists: endorsed by the Society for Cardiovascular Angiography and Interventions and the Society of Thoracic Surgeons. Circulation 2006, 114: e84-e231.

21. Freeman RV, Otto CM: Spectrum of calcific aortic valve disease: pathogenesis, disease progression, and treatment strategies. Circulation 2005, 111:3316-3326

22. Poggianti E, Venneri L, Chubuchny V, Jambrik Z, Baroncini LA, Picano E: Aortic valve sclerosis is associated with systemic endothelial dysfunction. J Am Coll Cardiol 2003, 41:136-141.

23. Agmon Y, Khandheria BK, Jamil Tajik A, Seward JB, Sicks JD, Fought AJ, O'Fallon WM, Smith TF, Wiebers DO, Meissner I: Inflammation, infection, and aortic valve sclerosis: Insights from the Olmsted County (Minnesota) population. Atherosclerosis 2004, 174:337-342.

24. Aronow WS, Ahn C, Shirani J, Kronzon I: Comparison of frequency of new coronary events in older subjects with and without valvular aortic sclerosis. Am J Cardiol 1999, 83:599-600.

25. Shah SJ, Ristow B, Ali S, Na BY, Schiller NB, Whooley MA: Acute myocardial infarction in patients with versus without aortic valve sclerosis and effect of statin therapy (from the Heart and Soul Study). Am J Cardiol 2007, 99:1128-1133.

26. Warren BA, Yong JLC: Calcification of the aortic valve: its progression and grading. Pathology 1997, 29:360-368.

27. Aikawa E, Aikawa M, Libby P, Figueiredo JL, Rusanescu G, Iwamoto Y, Fukuda D, Kohler RH, Shi GP, Jaffer FA, Weissleder R: Arterial and aortic valve calcification abolished by elastolytic cathepsin $S$ deficiency in chronic renal disease. Circulation 2009, 119:1785-1794.

28. Craver L, Marco MP, Martínez I, Rue M, Borràs M, Martín ML, Sarró F, Valdivielso JM, Fernández E: Mineral metabolism parameters throughout chronic kidney disease stages 1-5-achievement of K/DOQI target ranges. Nephrol Dial Transplant 2007, 22:1171-1176. 
29. Adeney KL, Siscovick DS, Ix JH, Seliger SL, Shlipak MG, Jenny NS, Kestenbaum BR: Association of serum phosphate with vascular and valvular calcification in moderate CKD. J Am Soc Nephrol 2009, 20:381-738.

30. Reichel H, Deibert B, Schmidt-Gayk H, Ritz E: Calcium metabolism in early chronic renal failure: Implications for the pathogenesis of hyperparathyroidism. Nephrol Dial Transplan 1991, 6:162-169.

31. Pitts TO, Piraino BH, Mitro R, Chen TC, Segre GV, Greenberg A, Puschett JB: Hyperparathyroidism and 1,25-dihydroxyvitamin $D$ deficiency in mild, moderate, and severe renal failure. J Clin Endocrinol Metab 1988, 67:876-881.

32. Kates DM, Sherrard DJ, Andress DL: Evidence that serum phosphate is independently associated with serum PTH in patients with chronic renal failure. Am J Kidney Dis 1997, 30:809-813.

33. Stewart BF, Siscovick D, Lind BK, Gardin JM, Gottdiener JS, Smith VE, Kitzman DW, Otto CM: Clinical factors associated with calcific aortic valve disease: Cardiovascular Health Study. J Am Coll Cardiol 1997, 29:630-634.

34. Aronow WS, Schwartz KS, Koenigsberg M: Correlation of serum lipids, calcium, and phosphorus, diabetes mellitus and history of systemic hypertension with presence or absence of calcified or thickened aortic cusps or root in elderly patients. Am J Cardiol 1987, 59:998-999.

35. Mohler ER, Sheridan MJ, Nichols R, Harvey WP, Waller BF: Development and progression of aortic valve stenosis: atherosclerosis risk factors-a causal relationship? A clinical morphologic study. Clin Cardiol 1991, 14:995-999.

36. Lindroos M, Kupari M, Valvanne J, Strandberg T, Heikkila J, Tilvis R: Factors associated with calcific aortic valve degeneration in the elderly. Eur Heart J 1994, 15:865-870

37. Boon A, Cheriex E, Lodder J, Kessels F: Cardiac valve calcification: characteristics of patients with calcification of the mitral annulus or aortic valve. Heart 1997, 78:472-472.

38. Peltier M, Trojette F, Sarano ME, Grigioni F, Slama MA, Tribouilloy CM: Relation between cardiovascular risk factors and nonrheumatic severe calcific aortic stenosis among patients with a three-cuspid aortic valve. Am J Cardiol 2003, 91:97-99.

39. Jander N, Minners J, Holme I, Gerdts E, Boman K, Brudi P, Chambers JB, Egstrup K, Kesäniemi YA, Malbecq W, Nienaber CA, Ray S, Rossebø A, Pedersen TR, Skjærpe T, Willenheimer R, Wachtell K, Neumann FJ, GohlkeBärwolf C: Outcome of patients with low-gradient "severe" aortic stenosis and preserved ejection fraction. Circulation 2011, 123:887-895.

doi:10.1186/1476-7120-9-31

Cite this article as: Masuda et al:: Impact of Chronic Kidney Disease on the Presence and Severity of Aortic Stenosis in Patients at High Risk for Coronary Artery Disease. Cardiovascular Ultrasound 2011 9:31.

\section{Submit your next manuscript to BioMed Central and take full advantage of:}

- Convenient online submission

- Thorough peer review

- No space constraints or color figure charges

- Immediate publication on acceptance

- Inclusion in PubMed, CAS, Scopus and Google Scholar

- Research which is freely available for redistribution 